ARCHIVO ESPAÑOL DE ARTE, LXXXIII, 332

OCTUBRE-DICIEMBRE 2010, pp. 347-362

ISSN: 0004-0428

\title{
PEDRO DE TOLEDO (1546-1627), V MARQUÉS DE VILLAFRANCA, COLECCIONISTA DE TAPICES
}

\author{
POR \\ Margarita García CALvo
}

El presente artículo da a conocer y estudia, en base a documentación inédita, la colección de tapices que tuvo Pedro de Toledo, V marqués de Villafranca. Esta documentación que aquí se aporta le sitúa entre los grandes coleccionistas de su época, al tiempo que permite identificar en la actualidad tapicerías que fueron de su propiedad.

Palabras clave: Pedro de Toledo; Fadrique de Toledo; Tapices; Tasación de bienes; Almoneda.

PEDRO DE TOLEDO (1546-1627), V MARQUIS OF VILLAFRANCA, TAPESTRY COLLECTOR

This article, based on heretofore-unpublished documents, presents and studies the tapestry collection of Pedro de Toledo, V Marquis of Villafranca. This documentation situates him among the greatest collectors of his time, while permitting the current identification of tapestries that once belonged to him.

Key words: Pedro de Toledo; Fadrique de Toledo; Tapestries; Valuation of goods; Auction.

La nobleza española de los siglos XVI y XVII fue dueña de valiosísimas colecciones de tapices, signo de lujo y magnificencia en la España de ese momento. Sus cargos políticos y militares en Flandes y también en Francia e Italia, favorecieron este afán coleccionista. Luis de Haro († 1661), marqués del Carpio ${ }^{1}$, Ruy Gómez de Silva († 1626), III duque de Pastrana ${ }^{2}$, o Luis Guillén de Moncada († 1672), duque de Montalto ${ }^{3}$, son algunos de los ejemplos más sobresalien-

\footnotetext{
${ }^{1}$ Burke, Marcus B., "Luis de Haro como ministro, mecenas y coleccionista de arte", en La almoneda del siglo. Relaciones artísticas entre España y Gran Bretaña, 1604-1655, Madrid, 2002, pp. 87-106.

${ }^{2}$ No sólo fue un gran coleccionista de tapices sino que patrocinó una manufactura en su villa que funcionó durante los años 1622 a 1633, dirigida por el tejedor flamenco François Tons. Ver a AsselBERGHS, Jean Paul ( $\dagger$ ), DeLmarCEL, Guy y García Calvo, Margarita, "Un tapissier bruxellois actif en Espagne: François Tons”, en Bulletin des Musées royaux d'Art et d'Histoire de Bruxelles, 56-2, 1985, pp. 89-121. García Calvo, Margarita, Tapices de Pastrana, Tesis Doctoral (inédita), 1995, pp. 130-171 y 182-291.

3 Delmarcel, Guy, García Calvo, Margarita, Brosens, Koenraad, "Spanish Family Pride in Flemish Wool and Silk: the Moncada and Their Baroque Tapestry Collection", en Tapestry in the Baroque. Threads of Splendor. Procee-
} 


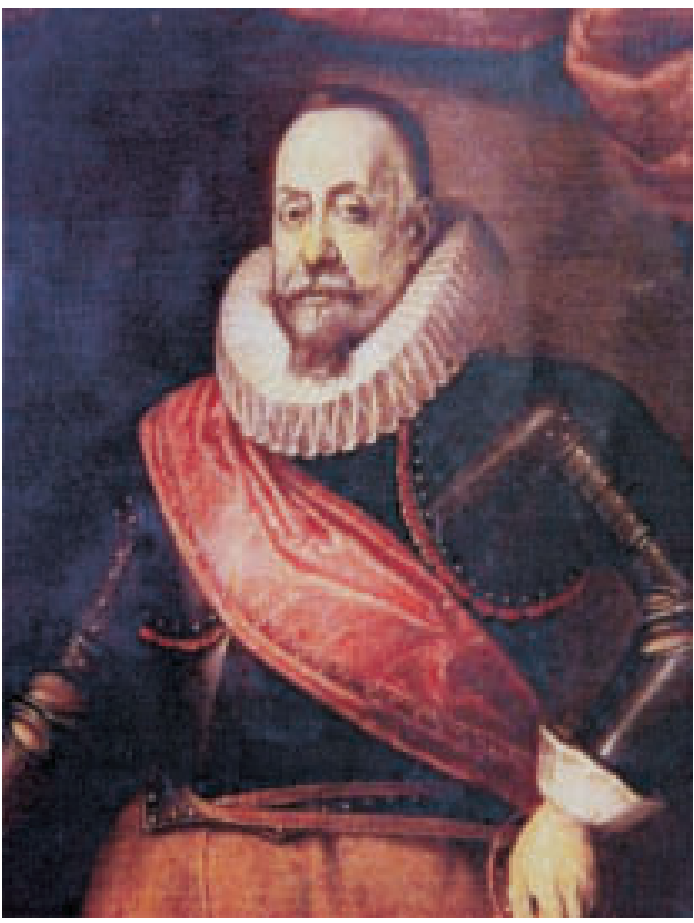

Fig. 1. Retrato de Pedro de Toledo, V marqués de Villafranca. Colección particular.

tes en el siglo XVII de esta nobleza, nombres a los que podríamos añadir el de Pedro de Toledo, V marqués de Villafranca del Bierzo, II duque de Fernandina y príncipe de Montalbán, nieto del famoso virrey de Nápoles del mismo nombre (fig. 1).

Nacido en Nápoles el 5 de septiembre de 1546, ocupó diferentes cargos militares y políticos a lo largo de su vida. General de las Galeras de Nápoles hasta 1595, es cesado tras un viaje a Malta y, viudo ya de su primera esposa, Elvira de Mendoza, con quien tuvo a sus cuatro hijos, se retira a Villafranca, para pocos años después volver de nuevo a Italia como Gobernador y Capitán General en Milán. Su siguiente destino fue el de embajador en París, a donde en 1608 decide enviarle Felipe III con la misión de obtener la colaboración de Enrique IV en las negociaciones de paz en Flandes. En 1614 regresa a Italia como Gobernador de Milán, hasta el año 1618 en que vuelve a España, siendo premiada su política en esta última ciudad italiana con la Grandeza de España. A su muerte, el 17 de julio de 1627, le sucede en el marquesado de Villafranca su hijo García de Toledo y Mendoza $^{4}$.

Poco antes de fallecer manda hacer la tasación de su colección de tapices, que se da a conocer en esta publicación ${ }^{5}$ (fig. 2).

\section{Tasación de tapicerías en el año 1627}

Son 111 los tapices que se mencionan en este documento, formando parte de 14 series, algunas de ellas muy codiciadas entre los grandes coleccionistas de su tiempo. En él se hace una descripción pormenorizada de la mayor parte de las tapicerías, indicando su lugar de procedencia.

dings of the International Symposium. The Metropolitan Museum of Art, New York, October 20-21-2007, edited by Thomas P. Campbell, New York, MMA (en imprenta).

${ }^{4}$ Las casas incorporadas. Cuadernos Fundación Casa Medina Sidonia, n. ${ }^{0}$ 6, 2003, pp. 11-12.

${ }^{5}$ La mayor parte de la documentación utilizada para este artículo se conserva en el Archivo de Medina Sidonia (Sanlúcar de Barrameda). Desde aquí quiero dar las gracias a Liliane Maria Dahlmann, presidenta de la FCMS por las facilidades dadas para la consulta de los fondos del archivo. ADMS, leg. 4885. Apéndice. Esta tasación la manda hacer Pedro de Toledo pocos meses antes de fallecer, ya que quiere conocer el valor de sus "tapicerias, alfombras y demas cosas de su guardarropa" Previamente a la tasación se entrega a Pedro Bergeret las tapicerías que hay en el guardarropa. En esta relación hay tres tapicerías que quedan fuera de la tasación posterior sin que sepamos el motivo, y que son: "Monteria y payses" una "Historia de audinarda" y una "Historia de Alejandro". También en la tasación se incluyen otras cinco colgaduras que no aparecían en la relación del guardarropa: "marco antonio y cleopatra", "anteón y boscajes", "julio cesar", "las metamorfosis" y los reposteros. 


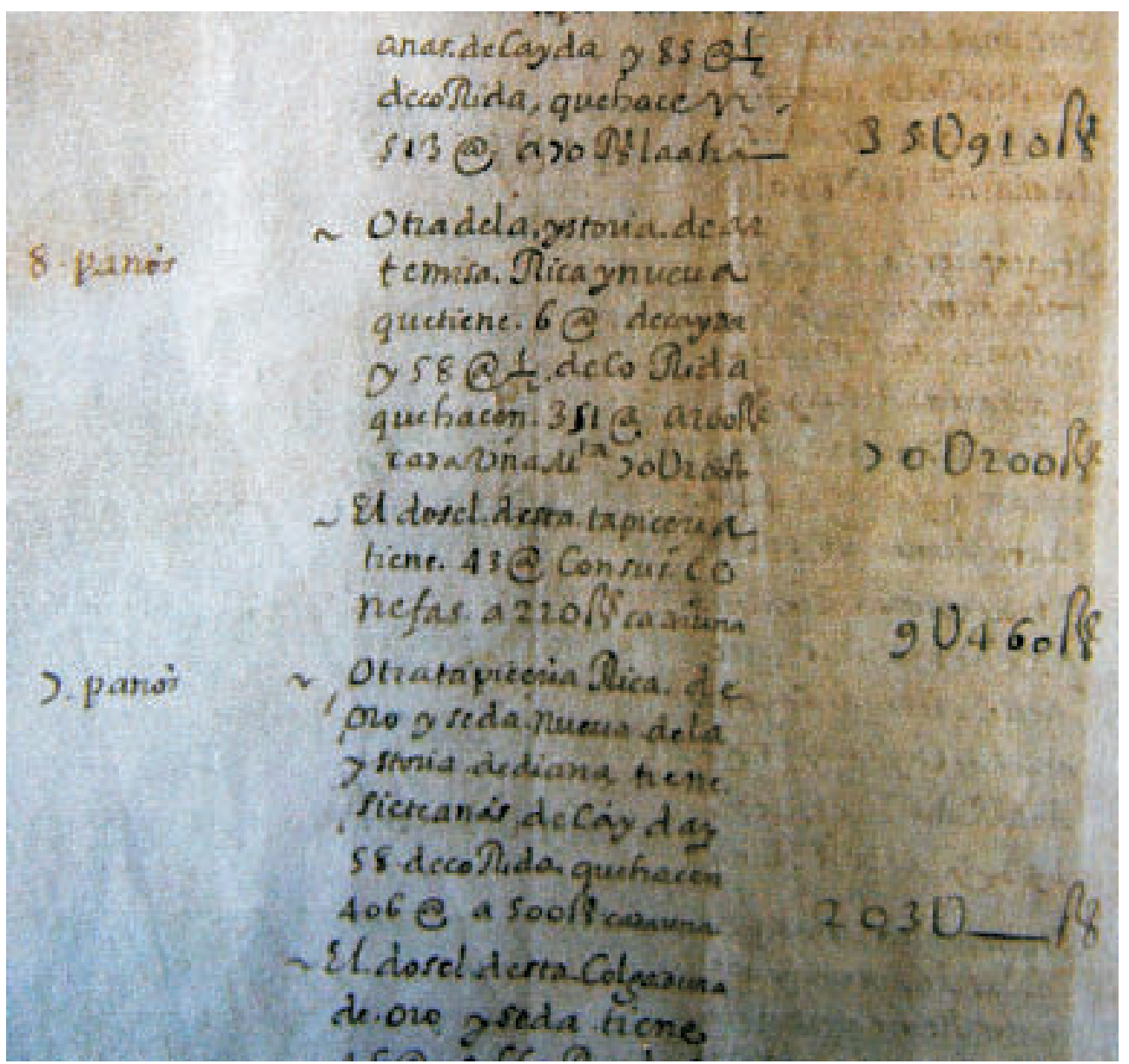

Fig. 2. Tasación de los tapices de Pedro de Toledo. Año 1627. Archivo de Medina Sidonia. Legajo 4885.

Así vemos que predominan las tejidas en Flandes: siete conjuntos, de los que cuatro son de Bruselas, el centro de producción más importante de los Países Bajos Meridionales ya desde finales del siglo XV: una Historia de Alejandro, otra de Marco Antonio y Cleopatra, unas Fábulas de Acteón y boscajes y unas Galerías. De Enghien se cita una Historia de Faetón. A Audenarde se le atribuyen unas Historias y a Flandes, sin especificar el lugar en concreto, una Historia de Sansón. Todos ellos son calificados como "finos", exceptuando el de Audenarde, al que se refiere como de "lana vasta". De París también tiene D. Pedro tres tapicerías: una Historia de Julio César, otra de Diana y una de Artemisa, siendo estas dos últimas calificadas como "ricas y nuevas". Del resto de las series no se dice su lugar de procedencia, y son una Historia de Alejandro, unas Metamorfosis, una de Montería y payses (también calificada como "tapicería basta") y diez reposteros de tapicería.

Las preferencias en cuanto a la temática se reparten fundamentalmente, como vemos, entre los temas de historia antigua (Alejandro, Marco Antonio y Julio César) y los mitológicos (Faetón, Acteón, Metamorfosis y Diana). Completan la colección un tema alegórico (Artemisa), otro del Antiguo Testamento (Sansón), las Galerías, el de Montería y el denominado de Historias, además de los reposteros con sus armas, imprescindibles en las colecciones de la 
alta nobleza para realzar su linaje. Preferencias que no difieren mucho de las de otros afamados coleccionistas contemporáneos que buscaban temas ejemplares extraídos de la historia antigua, que tenían como protagonistas a egregios personajes como Alejandro o Julio César, con los que poder compararse en las virtudes que éstos habían encarnado: la clemencia, el valor... También tuvieron gran éxito los temas alegóricos tradicionales o las escenas de las Metamorfosis de Ovidio $^{6}$.

De las series de este documento de 1627 alguna es heredada, como es el caso de la de Sansón, comprada por su padre, García de Toledo, en 1549, en Flandes: "una tapiçeria rica dela ystoria de sansón de 6 anas de alto que tienen 534 anas"7. Otras fueron adquiridas por Pedro de Toledo en sus estancias en Francia e Italia. En este último país, en 1602, teniendo como intermediario a Julio Spinola, compra unos reposteros, para los cuales envía desde Nápoles los dibujos para que se los hagan en Milán con mucha prisa debido a que su hijo va a contraer matrimonio y éste los quiere tener en ese momento: “...veinte y quattro reposteros... que de tela de Florencia me los hagan en Milan bien recamados según el dibujo que va en una de las caxas añadiendo el friso que sea un poco mas ancho y todo perfilado de oro quam rico pudiese ser y retocado de seda y de pintura en donde fuese neceser y sean todos 24 conforme al dibujo diferenciando solo en los colores de carmesí y negro, siya a us. no le pareciese hacer los 12 desta manera y los otros 12 de otro disinio si alla le hubiese mejor con que las Armas sean las mismas..." . Parece que sólo llegaron a hacerse diez de estos reposteros, que son los que se mencionan en un inventario de guardarropa, hecho en Villafranca en el $1607^{9}$, y también en el que se hace a su muerte ${ }^{10}$.

En el año 1601 los tejedores flamencos Marc de Comans, de Amberes, y su cuñado François de La Planche, de Audenarde, se instalan en París alentados por el rey Enrique IV. Comans, en el Faubourg Saint Marcel, y La Planche, en el antiguo Palais des Tournelles. En 1607 se unen ambos talleres y los tejedores flamencos reciben cartas patentes del rey para gestionar su manufactura en condiciones muy favorables: exenciones fiscales, monopolio, prohibición de importar tapices extranjeros a Francia... La calidad del tejido, la riqueza decorativa y los ricos materiales empleados en los tapices que se hacían en este taller los hizo ser muy valorados. El aprecio de Pedro de Toledo se pone de manifiesto en las dos tapicerías que les compra en su época de embajador en París. La Historia de Artemisa la adquiere en $1610^{11}$. Un año antes había encargado la Historia de Diana. La compra de esta última, que pertenece actualmente a Patrimonio Nacional ${ }^{12}$ (fig. 3), fue azarosa por los problemas económicos que tenía el $\mathrm{V}$ marqués en ese momento, y así lo refleja su correspondencia con Alexandre Yeregli, su agente en París, desde septiembre de 1609 hasta noviembre de 1610. Desde esta ciudad, Yeregli le comenta a D. Pedro la tensa situación que hay con "Coymans" y con Alexandre Terreille debida al impago de la tapicería, de la que ya tenía en su poder dos tapices desde septiembre de 1609 (por lo menos). "Coymans" ha decidido "poner en justicia" a Yeregli, al mismo tiempo que está dispuesto a vender la tapicería si en dos meses no se la pagan. El agente le dice al noble que sería una pena que ocurriese esto último "...principalmente por tener las armas de V. Exca. y que los dos tapices que tiene no le podrían servir y sería

\footnotetext{
${ }^{6}$ CAmpbell, Thomas P., "Suntuosidad, frescos de seda, enseres de lujo: la tapicería en su contexto, 1600-1660", en Hilos de esplendor. Tapices del Barroco, Madrid, 2008, pp. 107-121.

7 ADMS, leg. 1460.

8 ADMS, leg. 4391.

9 ADMS, leg. 1658.

10 ADMS, leg. 4885. Apéndice.

11 Coural, Jean, Chefs-d'oeuvre de la Tapisserie parisienne, 1597-1662, París, 1967, pp. 19 у 28.

12 Junquera, Paulina y Díaz Gallegos, Carmen, Catálogo de Tapices de Patrimonio Nacional, vol. II: Siglo XVII, Madrid, 1986, pp. 6-14.
} 


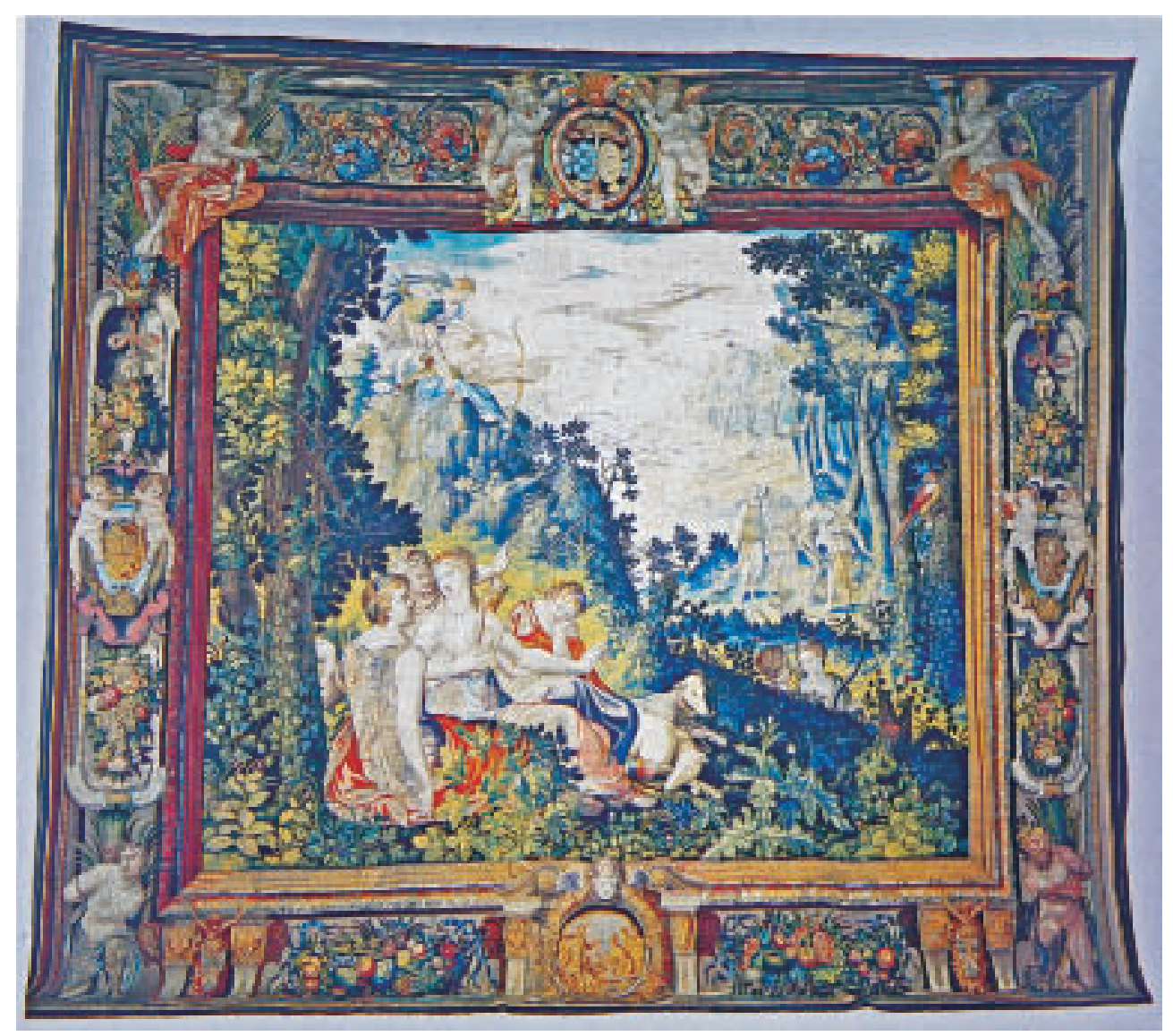

Fig. 3. Tapiz de "Diana con sus ninfas descansando en el bosque", Historia de Diana. Patrimonio Nacional, Madrid.

cosa hecha inútilmente"13. Por fin, en marzo de 1610, Yeregli recibe de Pedro de Toledo el dinero para pagar la tapicería: 70.200 reales (aún faltaban mil) y se lamenta de que el retraso de un año le ha obligado a él a anticipar la mitad de la deuda a "Coymans" para evitar la venta y su propio ingreso en prisión ya que el tejedor le había perseguido judicialmente ${ }^{14}$. No será hasta noviembre de 1610 cuando se le notifique a D. Pedro que dos cajas de tapicería han salido de París camino de Irún con el duque de Feria, después de las gestiones que ha hecho Íñigo de Cárdenas. La mención de las armas tejidas en los tapices es lo que nos lleva a identificar la tapicería de la que se habla en esta correspondencia con la Historia de Diana, ya que es la única de París que en 1627 se dice que tiene tejidas las "armas de Toledos y Ossorios"15.

13 ADMS, leg. 4393. Carta fechada en París, "al postrero de septiembre de 1609". Esta correspondencia viene en el legajo citado y en los números 4399, 4412 y 4416. Esta documentación fue publicada por WATTENBERG, Eloisa, "La presentación del libro y de la espada: un tapiz de la historia de Artemisa en Valladolid", en Boletín del seminario de estudios de Arte y Arqueología, t. LX, Valladolid, 1994, pp. 480-484. La autora de este artículo identifica erróneamente la tapicería citada en las cartas entre Pedro de Toledo y su agente con la Historia de Artemisa.

14 ADMS, leg. 4393. Carta fechada en París, 14 de marzo de 1610.

15 ADMS, leg. 4885. Apéndice. 
Tanto la Historia de Diana como la de Artemisa se tejieron en repetidas ocasiones en las manufacturas parisinas. La primera estuvo siempre entre los temas predilectos de los tejedores porque les permitía demostrar su habilidad en el tratamiento de la vegetación, a la vez que representar escenas de caza, pasatiempo favorito de la nobleza. De hecho, se han identificado más de 130 tapices pertenecientes a 28 conjuntos diferentes. La Historia de Diana fue diseñada originalmente por el artista de la corte Toussaint Dubreuil (h. 1561-1602) para Enrique IV de Francia. El rey recuperó un proyecto artístico anterior como inspiración para su diseñador, una tapicería de la Historia de Diana, tejida para Diana de Poitiers medio siglo antes. Dubreuil incorporó elementos novedosos a los diseños de esta tapicería, como las figuras monumentales y el dinamismo de las composiciones que le acercan al espíritu del barroco. Las primeras ediciones de Diana fueron encargos. Dos fueron para Enrique IV, aunque ninguna de ellas se conserva, y otra de las primeras ediciones por encargo fue la de Pedro de Toledo, con sus armas en la cenefa superior. En otras ocasiones fueron series para el mercado. El cardenal Richelieu (Mobilier National, París) o la condesa de Soissons, María de Borbón (Palazzo Reale, Turín, y Ashmolean Museum, Oxford) fueron otros de sus propietarios ilustres ${ }^{16}$.

De Artemisa, descrita en la tasación como "rica y nueva"17, se tejieron en el taller del Faubourg Saint Marcel, en los primeros decenios del siglo XVII, más de 22 juegos, unos 200 paños, dos de cada tres tejidos con hilos de oro. El poema titulado "La historia de la reina Artemisa", que toma como base al personaje histórico, fue compuesto hacia 1561 por Nicolas Houel como homenaje a Catalina de Médicis, que había quedado viuda, viéndose en la obligación de educar a su hijo para ser rey de Francia. Houel alaba el luto que lleva la protagonista del poema, Artemisa, por su marido y sus esfuerzos para educar a su hijo de acuerdo con su alcurnia, insinuando un paralelismo con la situación que vivía en ese momento Catalina de Médicis y su hijo, el futuro Carlos IX, tras la muerte de su esposo Enrique II, rey de Francia. El pintor de corte Antoine Caron (1512-1599) hizo los dibujos para ilustrar este texto, pensando en que fuesen utilizados como diseños en las manufacturas de tapices, aunque nunca se les dio ese uso para Catalina. A principios del siglo XVII resurge el proyecto y varios artistas parisinos, Henri Lerambert y Laurent Guyot entre otros, preparan los cartones de las series que se van a hacer en los talleres del Louvre, del Faubourg Saint Marcel... Además de Pedro de Toledo, poseyeron conjuntos de Artemisa Enrique IV, María de Médicis y Luis XIII, el cardenal Francesco Barberini (en Minneapolis Institute of Arts), el archiduque Maximiliano III de Austria (Residenz, Munich), entre otros ${ }^{18}$.

Este aprecio por los talleres parisinos ya lo tuvo su padre García de Toledo $(† 1578)$, que en el año 1566 se refería a las armas que había que poner en unos paños que le estaban haciendo en París. También los archivos proporcionan noticias de sus compras en Italia en los años 15581561, de tapices labrados de seda, teniendo como intermediario a Juan Jacomo Cataneo, miembro de la conocida familia de comerciantes genoveses.

Con anterioridad a las adquisiciones de Pedro de Toledo en Italia y París, en los años 15841585, en un "cuaderno de gastos" se menciona otra compra: "ocho paños de tapicería muy fina, nueva de Bruselas de galerías de quatro anas de cayda y todas son ciento y setenta anas" 19 . Estas

${ }^{16}$ La bibliografía es muy abundante. Ver el estudio reciente de DenIs, Isabelle, "Los talleres de París, 1590-1650", en Hilos de esplendor. Tapices del Barroco, Madrid, 2008, pp. 123-169.

17 ADMS, leg. 4885. Apéndice.

${ }^{18}$ La bibliografía sobre estos tapices es muy numerosa. Ver Adelson, Candace, European Tapestry in the Minneapolis Institute of Arts, Minneapolis, 1994, pp. 160-288. BreJon de LAVERGNÉE, Arnauld, y VitTET, Jean, Á l'origine des Gobelins. La Tenture d'Artémise. La redécouverte d'un tissage royal, Paris, Galerie des Gobelins, 12 mai 2007-30 septembre 2007. Denis, Isabelle, op. cit. VitTET, Jean y BREJON DE LAVERGNÉE, Arnauld, La collection de tapisseries de Louis XIV, Dijon, 2010, pp. 50-55, 70-75 y 299-305.

19 ADMS, leg. 5483. 


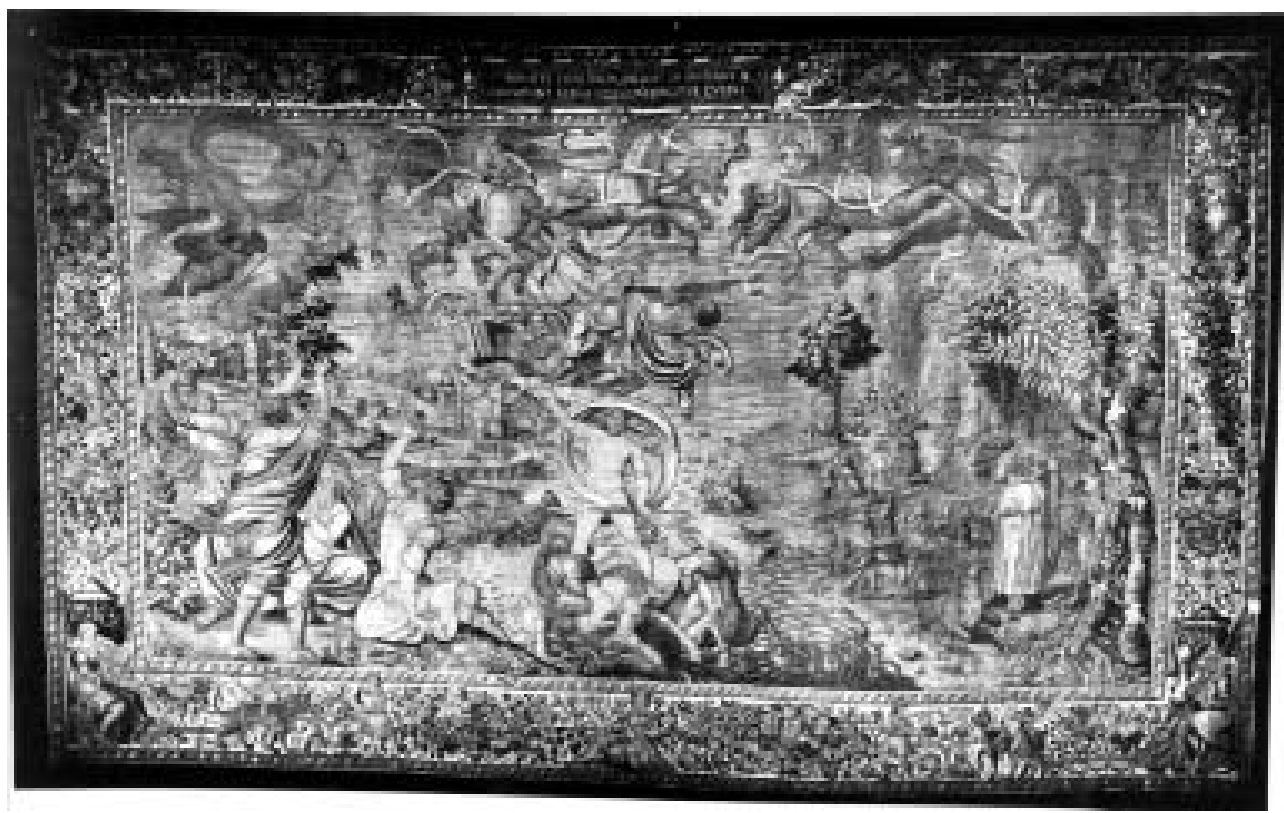

Fig. 4. Tapiz de "La caída de Faetón”, Historia de Faetón. München (Bayerische Schlösserverwaltung Museumsabteilung).

Galerías o Pérgolas, con columnas, jarrones con flores, paisajes de fondo, en donde se incluyen a veces animales o escenas de caza, tuvieron un gran éxito en la segunda mitad del siglo XVI y todo el XVII.

De todas las tapicerías de D. Pedro, de la única que tuvo dos ediciones fue de la Historia de Alejandro. Una, de ocho paños, fue tejida en Bruselas y la otra tiene como característica destacada llevar "bolateria en las cenefas". Las cenefas de esta segunda son las muy conocidas de los "cuatro elementos", que se utilizaron por vez primera por expreso deseo de Felipe II en una Vida de Noé, encargada al taller de Guillermo Pannemaker en el año 1563, y que se siguieron usando hasta más de medio siglo después, lo que nos permite fechar aproximadamente esta Historia de Alejandro, de la que no se dice su procedencia. Estas mismas cenefas "de bolateria" las tiene la tapicería de Marco Antonio y Cleopatra, tejida en Bruselas, de la que hablaremos más adelante, y la denominada de Galerías.

También se menciona el lugar de origen de otras series, como la Historia de Faetón, hecha en Enghien, lo que resulta interesante ya que algunas piezas conservadas actualmente nos permiten hacernos una idea de cómo eran las de D. Pedro. Es el caso de un tapiz de La caída de Faetón con marca de la ciudad de Enghien, tejido en el tercer cuarto del siglo XVI, que se conserva en München (Bayerische Schlösserverwaltung Museumsabteilung) ${ }^{20}$ (fig. 4) y que coincide con el de nuestra tasación no sólo en cuanto a la ciudad de procedencia sino que también es de una fecha aproximada. Las escenas de la Historia de Faetón se inspiran en las Metamorfosis de Ovidio (libro II, 304-324) y fueron tejidas en los talleres de Bruselas en el segundo cuarto del siglo XVI y unos años después en Enghien, siguiendo los mismos modelos. Parece que este tema

${ }^{20}$ Crick-KuntZiger, M., "Note sur une tenture inedited de l'Histoire de Phaéton", en Revue belge d'archéologie et d'histoire de l'art, XX, 1951, pp. 132-133. Delmarcel, Guy, Tapisseries anciennes d'Enghien, Mons, 1980, pp. 64-65. 
era puesto como ejemplo de los castigos divinos que podían afligir al soberano temerario y excesivamente ambicioso. A otro centro de producción flamenco, Audenarde, se le atribuyen unos tapices cuyos temas son unas Historias. Tanto los asuntos bíblicos como los de la historia antigua estuvieron muy de moda en los talleres de esta ciudad entre 1560 y 1620 , y muy posiblemente en estos paños estuviese tejido uno de estos temas.

Aunque de una parte de los tapices que aparecen en esta tasación no tenemos documentación sobre su compra, sí tenemos de otras adquisiciones que hizo en sus estancias en Italia y Malta y que no se reflejan en el citado documento, además de su interés por otras series que no sabemos si llegaron a ser de su propiedad. Todo ello le presenta como un coleccionista muy dinámico, buen conocedor de las mejores tapicerías de la época, tanto flamencas como francesas e italianas, algunas de las cuales, como estamos viendo, pasaron a formar parte de su colección.

\section{Otros tapices de Pedro de Toledo que no se reflejan en la tasación de 1627}

Los ciento once tapices que aparecen en la documentación de 1627 no fueron los únicos que tuvo el marqués de Villafranca. Según las noticias que proporcionan los archivos, otros más fueron de su propiedad en algún momento de su vida, aunque no los tenía unos meses antes de fallecer. Por una carta de enero de 1596 conocemos su interés en comprar una tapicería en Malta que venden "los señores del Tesoro" y es informado por su agente de que "...el ayre de marina la tiene gastada y que las Bodas de Jupiter no es ystoria para la iglesia..." ${ }^{21}$. D. Pedro está dispuesto a recogerla en Mesina o en Malta, lugar este último que conocía bien por haber desembarcado allí en varias ocasiones siendo General de las Galeras. Ya su padre, sirviendo a Felipe II, había defendido la isla de los ataques de los turcos en 1565. Aún ha de pasar un año para que la compra se haga efectiva: en enero de 1597, el obispo de Malta, Tomás Gargal, escribe a D. Pedro: "he recibido mucha merced con la carta de V. Ex. ${ }^{\text {a }}$ y assi luego trate con el señor Gran Comendador y Gnal Santubin sobre la tapizeria desea V. Ex. ${ }^{\mathrm{a}}$ y me dixo el orden tenia. Se ha tratado en Consejo y concluydo de darla a V.Ex. ${ }^{a}$ por onze mil escudos de doze tarines por escudo, y este es el ultimo preçio porque la religión la tuvo por catorze mil escudos, como entenderá V.Ex. ${ }^{a}$ mas largamente por dicho gran Comendador, y en todo lo demás que V.Ex. ${ }^{a}$ me conoçera bueno reçibire mucha merced que me mande..."22.

Una serie de los "Amores de Júpiter" fue tejida para Andrea Doria sobre diseños de Perino del Vaga a comienzos de la década de 1530 y adornó el palacio Doria hasta que en 1644 un descendiente de Andrea la regaló al almirante de Castilla. En 1647, a la muerte del almirante, se muestra muy interesado por ella el cardenal Mazarino, pero expresa su preocupación sobre si el tema estaría tratado decentemente, desistiendo finalmente de comprarla, lo que corrobora la opinión que le transmite a $\mathrm{D}$. Pedro su agente de que no era un tema adecuado para la iglesia. La riqueza de esta colgadura, que no ha llegado hasta nuestros días, parece que era excepcional, siendo considerada la mejor que había venido de Flandes a Italia en esa época. No se conocen más tapices de este tema tejidos en el siglo XVI, lo que no excluye la posibilidad de que se hubiese hecho una segunda edición de los cartones Doria, que fuese la que compró D. Pedro en Malta y que tampoco habría llegado hasta el presente. También podría ser que las Bodas de Júpiter del marqués de Villafranca se tejiesen por modelos diferentes de los de Andrea Doria. Actualmente hay un tapiz de este mismo tema, "Amores de Júpiter e Io", tejido hacia 1530-1550, en la colección Selgas Fagalde (Cudillero, Asturias) ${ }^{23}$.

\footnotetext{
21 ADMS, leg. 4406.

22 ADMS, leg. 4391.

23 García CAlvo, Margarita, Colección de Tapices de la Fundación Selgas Fagalde, Madrid, 2009, pp. 30-31.
} 
Un año después, en 1598, está gestionando otra compra que no sabemos si llegó a materializarse y recibe un paño de muestra para que lo vea y así saber cuánto se puede pagar. La tapicería la vende Julio de Uribe. Le dice el agente, Francisco Tellez, a Pedro de Toledo que "si el precio de los paños contentase tanto como la vista dellos de acuerdo estaríamos juan de urive y yo...y temiendo herrar contra su gusto de Vex. equerido sin hazer precio enviar este paño para que Vex. le vea y pareciéndole a propósito me mandara avisar lo que le parece que se podrá dar por el anna porque Juan de urive aviendome pedido doce ducados, a dado fondo en diez...por ultima resolución..." También le dice el agente que "...los demas paños son de la misma suerte aunque no todos con tantas figuras como este..."24.

En septiembre de 1602 vuelve de una de sus estancias en Italia y se hace un "inventario de recamara", en Cartagena, de todo lo que trae y de cómo va a quedar distribuido entre esta residencia y la de Villafranca. Trae consigo la tapicería de Malta de los Amores de Júpiter, que había comprado pocos años antes, y una nueva colgadura, comprada en aquel país, de la "ystoria de Jose". Esta última va destinada a Villafranca, quedando registrada en los inventarios de recámara de 1603 como los "panni dell Historia di Gioseph", que son "diez y nueve piecas grandes y pequeñas, que es de seda bordada de oro y plata y las cenefas de terciopelo verde ordadas de oro a follages aforrados todos los paños en lienzo teñido de verde" 25 . Actualmente se conserva una Historia de José en Florencia (Palacio Viejo), tejida entre 1550 y 1553 en Florencia, en el taller de Nicolás Karcher para Cosimo I ${ }^{26}$. Este conjunto de veinte tapices, tejido sobre diseños de Agnolo Bronzino y colaboradores, fue muy apreciado ya en su momento, lo que pudo animar a Pedro de Toledo a adquirir una colgadura del mismo tema y casi exacto número de piezas en una manufactura italiana que los archivos no precisan.

A punto de concluir su última estancia en Italia y reintegrarse definitivamente a España desde Milán en el año 1618, se interesa por una Historia de Noé de trece tapices. Jorge Landínez, que negocia sus compras junto al marqués de Bedmar, le dice que a este último le ha gustado la tapicería y ha decidido enviarle desde Venecia un paño junto con "la nota de la calidad y precio por si gustare de que se trate de compralla". Es "una tapicería de la historia de noe con treze panos de 87 bracos y medio, de alta 6 bracos son a quadro 525 bracos. A cinco escudos el braco de los de esta moneda de Venecia monta-----2625"27. Parece que esta compra llegó a realizarse y que los tapices vienen para España en el mismo 1618, aunque ni en los inventarios de recámara ni en la tasación de 1627 encontramos paños de este tema.

\section{La almoneda de 1635}

Esta almoneda que se hace del Guardarropa de Pedro de Toledo unos años después de su muerte, y que sirve para pagar a sus acreedores, dispersa su valiosa colección de tapices ${ }^{28}$.

24 ADMS, leg. 4419.

25 ADMS, legs. 1509 y 4995.

${ }^{26}$ Meoni, Lucia, Gli arazzi nei musei fiorentini. La collezione medicea. Catalogo completo. I. La manifattura da Cosimo I a Cosimo II (1545-1621), Livorno, 1998, pp. 123-141. De la misma autora, "Le Storie di Giuseppe. Il capalavoro dell'arazzeria fiorentina", en Giuseppe negli arazzi di Pontormo e Bronzino. Viaggio tra i tesori del Quirinale, Roma, 2010, pp. 193-266.

27 ADMS, legs. 301 y 4398.

28 ADMS, leg. 4995. "Guardarropa de Don Pedro de Toledo mi señor. Cuenta de lo que se vende de ella desde principios de septiembre. Año 1635". Los encargados del guardarropa eran los responsables de la conservación y colocación de los tapices y de otros tejidos valiosos. 
En diciembre de 1634 había fallecido en muy precarias condiciones humanas y económicas, según se refleja en su testamento, su segundo hijo Fadrique de Toledo (1580-1634), marqués de Villanueva de Valdueza ${ }^{29}$, el mayor valedor de su padre ante los pleitos puestos por el primogénito y heredero del marquesado de Villafranca, García de Toledo ( $†$ 1649), que consideraba que su padre había disminuido el mayorazgo en vez de aumentarlo ${ }^{30}$. Fadrique, antes de su caída en desgracia, había protagonizado destacadas actuaciones al servicio de Felipe IV como la recuperación para la Corona en 1626 de Bahía de San Salvador (Brasil) ${ }^{31}$, que estaba en poder de los holandeses, y gozaba de un gran reconocimiento en la Corte como poseedor de valiosos tapices. Ejemplos de esto último los proporcionan Brown y Elliot en su estudio sobre la decoración del Buen Retiro al mencionar que se le llegó a ofrecer en 1633 "25.000 ducados por una rica colgadura para decorar el Retiro" 32 , lo que pone de manifiesto también los altísimos precios que tenían los tapices, muy por encima del valor de la pintura. Los mismos autores se refieren a otro tapiz de Fadrique como el más valioso de los que estaban colgados en las estancias que miraban al jardín del Palacio del Retiro y que había sido cedido a regañadientes por su propietario ${ }^{33}$.

La documentación de esta almoneda de los tapices de D. Pedro refleja la venta de ocho conjuntos desde 1635 a 1637 y aunque no se mencionan los temas de éstos (con una única excepción que comentaremos más adelante), sí los compradores y las medidas, lo que permite en un caso identificar la tapicería en la actualidad y en otros saber qué series se venden, al comparar las medidas con las que se proporcionaban en 1627.

La primera mención en este registro de ventas es una "colgadura y dosel de oro y seda que se vendió para El retiro el año de 1633, asta oy 25 de setiembre de 1635 están cobrados-----falta de cobrar del dosel 24.680 reales" 34 . La cantidad que se paga es muy alta y tiene que referirse a la Historia de Diana (Patrimonio Nacional), "hecha en París, finísima con oro y plata... con las armas de Toledos y ossorios", que había alcanzado la tasación más alta (500 reales el ana y 660 en el dosel) en $1627^{35}$. Comprada para Felipe IV, era hasta el presente estudio la única tapicería que junto con la de Artemisa, cuyo paradero desconocemos (si es que ha llegado hasta nuestros días), se sabía que había sido de Pedro de Toledo ${ }^{36}$.

La decoración del Palacio del Buen Retiro supuso cuantiosos gastos y la adquisición de tapices para su decoración fue una de las partidas más cuantiosas. No parece haber sido, por otro lado, la Historia de Diana la única colgadura de Pedro de Toledo que pasó a formar parte de la colección real, pues en febrero de 1637 queda anotado que debe "el conde de Castrillo para El

${ }^{29}$ En su testamento de diciembre de 1634 manda Fadrique que "todos sus bienes los vendan y rematen en publica almoneda". Quiere ser enterrado en Villafranca al lado de su padre y deja como herederos a su mujer, Elvira Ponce de León, a sus dos hijas y al hijo póstumo, que será luego el VII marqués de Villafranca, al morir el VI marqués sin descendencia. ADMS, leg. 4495.

30 ADMS, leg. 5129.

31 Esta hazaña y su protagonista es el tema del cuadro "Recuperación de Bahía", pintado por Juan Bautista Maino en 1633 para el Salón de Reinos del Palacio del Buen Retiro, y que hoy está en el Museo del Prado.

32 Brown, Jonathan y Elliot, John H., Un palacio para el Rey. El Buen Retiro y la corte de Felipe IV, Madrid, 2003, p. 105

${ }^{33}$ BRown y ElLiot, op. cit., p. 110.

34 ADMS, leg. 4995.

35 ADMS, leg. 4885. Apéndice.

${ }^{36}$ Ms. 7797, f. $111 \mathrm{v}$, Biblioteca Nacional de Madrid (citado por BROwn y ElLIOT, op. cit., p. 105). En este manuscrito se menciona la compra de una serie de ocho tapices con las fábulas de Diana en el mismo año de 1633 para el Buen Retiro. Esta serie de Diana del manuscrito 7797 coincide con la de Pedro de Toledo en el número de tapices y en la fecha de entrada en el Retiro, pero no en las medidas, 261 anas y media, muy lejos de las 454 de la de aquél. También, el precio pagado por ana (52 reales) es excesivamente bajo si lo comparamos con los 500 reales por ana en que es tasada la de D. Pedro en la tasación de 1627, lo que me hace pensar que no se trata de la misma tapicería. 


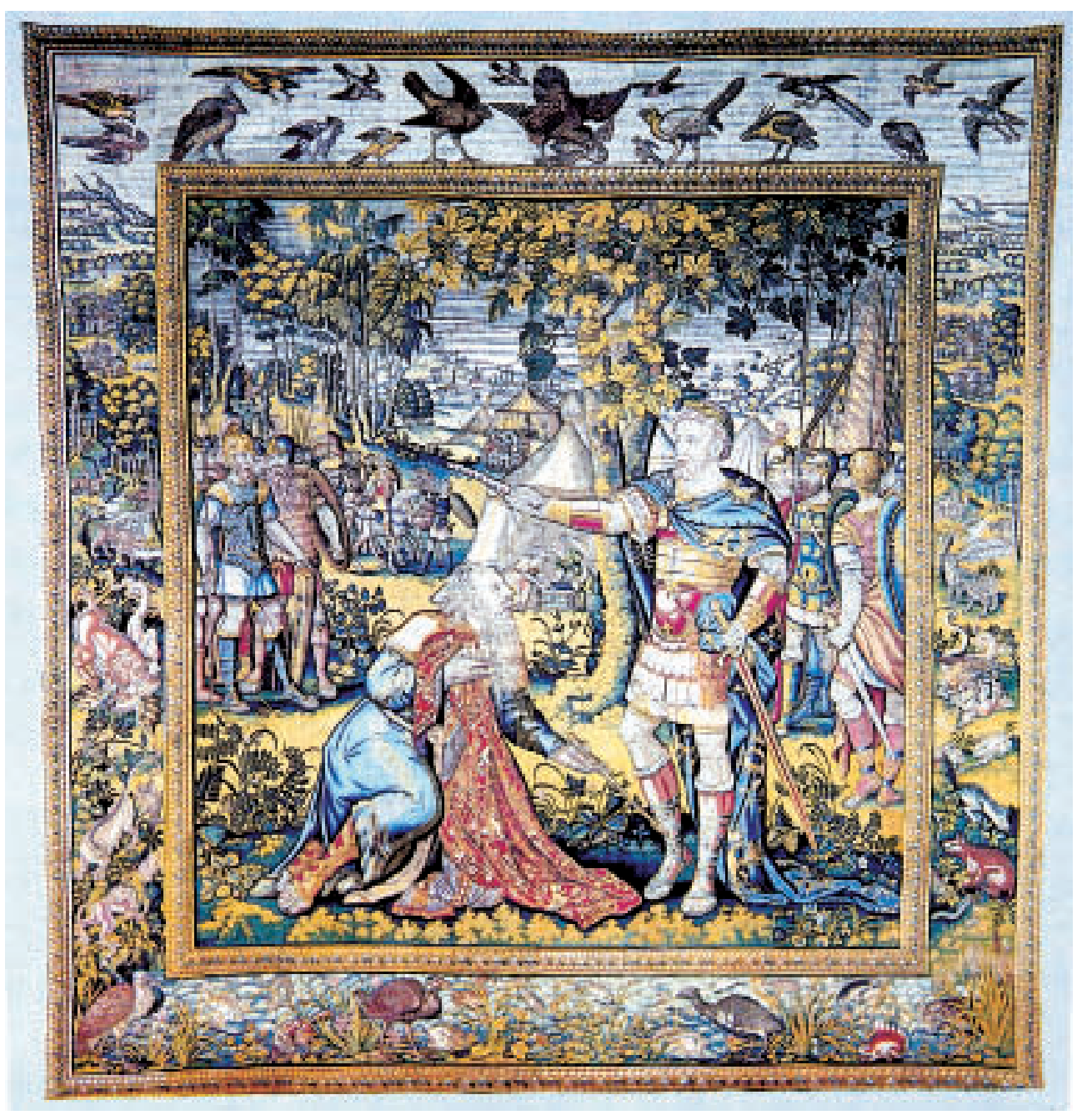

Fig. 5. Tapiz de "Octavio rehúsa las insignias de la soberanía", Historia del emperador Octavio. Patrimonio Nacional, Madrid.

retiro n. ${ }^{\circ}$ 5-----Tapicerias de 390 anas a 60 reales-----23.400 reales" ${ }^{\prime 37}$. Esta compra de García de Haro y Avellaneda, que era el que tomaba las decisiones en cuanto a la adquisición de tapices para el Retiro, parece ser la tapicería que en la tasación se describe como "...fina de Bruselas de la historia de Marco Antonio y Cleopatra con la cenefa alta de bolateria que tiene diez paños..."38. Descripción que se corresponde con la serie 51 de Patrimonio Nacional, identificada actualmente como la Historia del emperador Octavio (fig. 5), pero que en los inventarios palatinos en los que aparece a partir de la muerte de Carlos II (1700) es denominada como Historia de Marco

\footnotetext{
37 ADMS, leg. 4995.

38 ADMS, leg. 4885. Apéndice.
} 
Antonio y Cleopatra ${ }^{39}$. La cenefa alta "de bolateria" se refiere a las ya mencionadas cenefas de los "cuatro elementos", en las que el aire se representa en la parte superior por medio de numerosas aves. El éxito de estas cenefas hizo que se utilizasen frecuentemente desde 1563 hasta el primer cuarto del siglo XVII, como ya se ha dicho.

Otra venta que se hace es la Historia de Sansón, que había heredado D. Pedro de su padre: "debe Don Luis de Haro en 26 de abril de 1637 n. ${ }^{\circ} 10$-----Tapicerias la de sansón que tiene 508 y media a 40 reales son-----20.340 reales" ${ }^{40}$. El nuevo propietario es el $6 .^{\circ}$ marqués del Carpio, uno de los coleccionistas más importantes del siglo XVII por las valiosísimas compras de tapices y pinturas que hizo en la llamada "almoneda del siglo", que tuvo lugar a la muerte de Carlos I de Inglaterra ${ }^{41}$. La tapicería aparece posteriormente en el inventario de bienes libres que se hace a la muerte de Catalina Fernández de Córdoba ( $† 1647)$, mujer de Luis de Haro ${ }^{42}$. En la repartición de bienes, en 1650, es adjudicada a su viudo ${ }^{43}$. Unos años después, en 1658 y 1661, dispone $\mathrm{D}$. Luis en su testamento y codicilo qué tapicerías quiere que queden vinculadas al mayorazgo, entre las que no va a figurar la de Sansón, y manda que las demás sean vendidas en pública almoneda para pagar deudas ${ }^{44}$, pero tampoco va a ser su caso ya que en 1688 se incluye en el inventario de bienes a la muerte de Gaspar de Haro, nuevo marqués del Carpio. La descripción que se hace en este inventario es interesante ya que por vez primera se habla del tipo de cenefas que tiene: "Otra tapizeria de sanson que son onze paños antiguos de Bruselas de zenefas de follajes y tiene seis anas de cayda y ochenta y cinco menos una quarta de corrida que hacen todas en quadro quinientas y ocho anas y media" ${ }^{45}$. En 1689 se hace una almoneda de estos bienes, de la que sólo hay documentación parcial que no nos permite saber si fue vendida o no en ese momento $^{46}$, pero en el año 1733, el marquesado de Carpio se incorpora a la Casa de Alba y no aparece en los inventarios de esta Casa.

Actualmente se conservan cinco tapices de la Historia de Sansón con "cenefas de follajes" y de una época aproximada en la catedral de Tarragona ${ }^{47}$, donados, al parecer, por el arzobispo Gaspar Cervantes de Gaete en $1575^{48}$. El interés de las jerarquías de esta catedral por el arte de la tapicería les llevó a participar en la almoneda de Gaspar de Haro, en la que quizás se vendieron los tapices de Sansón, como se acaba de decir. Juan Carreras, prior mayor, intenta comprar nada menos que los famosos Hechos de los apóstoles, tejidos sobre modelos de Rafael, y ofrece tres doblones de oro por ana, pero la compra no llega a buen término porque la colgadura queda vinculada ${ }^{49}$. El ayuntamiento de Ávila tiene también un tapiz de Sansón de las mismas características, con cenefas "de follaje", procedente de la antigua colección de los condes de Superunda, los Manso de Velasco (fig. 6). La escena que se puede ver al fondo, a

39 Junguera, Paulina y Herrero Carretero, Concha, Catálogo de Tapices de Patrimonio Nacional, vol. I: Siglo XVI, Madrid, 1986, pp. 314-324.

40 ADMS, leg. 4995.

${ }^{41}$ BURKe, Marcus B. op. cit.

42 AHPM (Archivo Histórico de Protocolos de Madrid), prot. 6239, fol. 18v. Este inventario es citado por BURKE, Marcus B., op. cit., p. 91, nota 25.

43 AHPM, prot. 6239, fols. 651-653.

44 AHPM, prot. 6292, fols. 453v y 454. Este testamento es citado por Burke, Marcus B., op. cit., pp. 103-104.

45 AHPM, prot. 9819, fol. 813.

46 AHPM, prot. 9819, fols. 1123v-1196.

47 Morera y Llauradó, Emilio, Memoria o descripción histórica-artística de la santa iglesia catedral de Tarragona desde su fundación hasta nuestros días, Tarragona, 1904, pp. 160-161. BAtLle Huguet, Pedro, Los tapices de la catedral primada de Tarragona, Tarragona, 1946, pp. 9-10 y 51-54.

${ }^{48}$ CAPdevila, S., "Les antigues institucions escolars de la Tarragona restaurada", en Estudis Universitaris catalans, vol. XII, 2 (julio-diciembre), 1927, p. 152.

49 AHPM, prot. 9819, fols. 1190-1192v. 


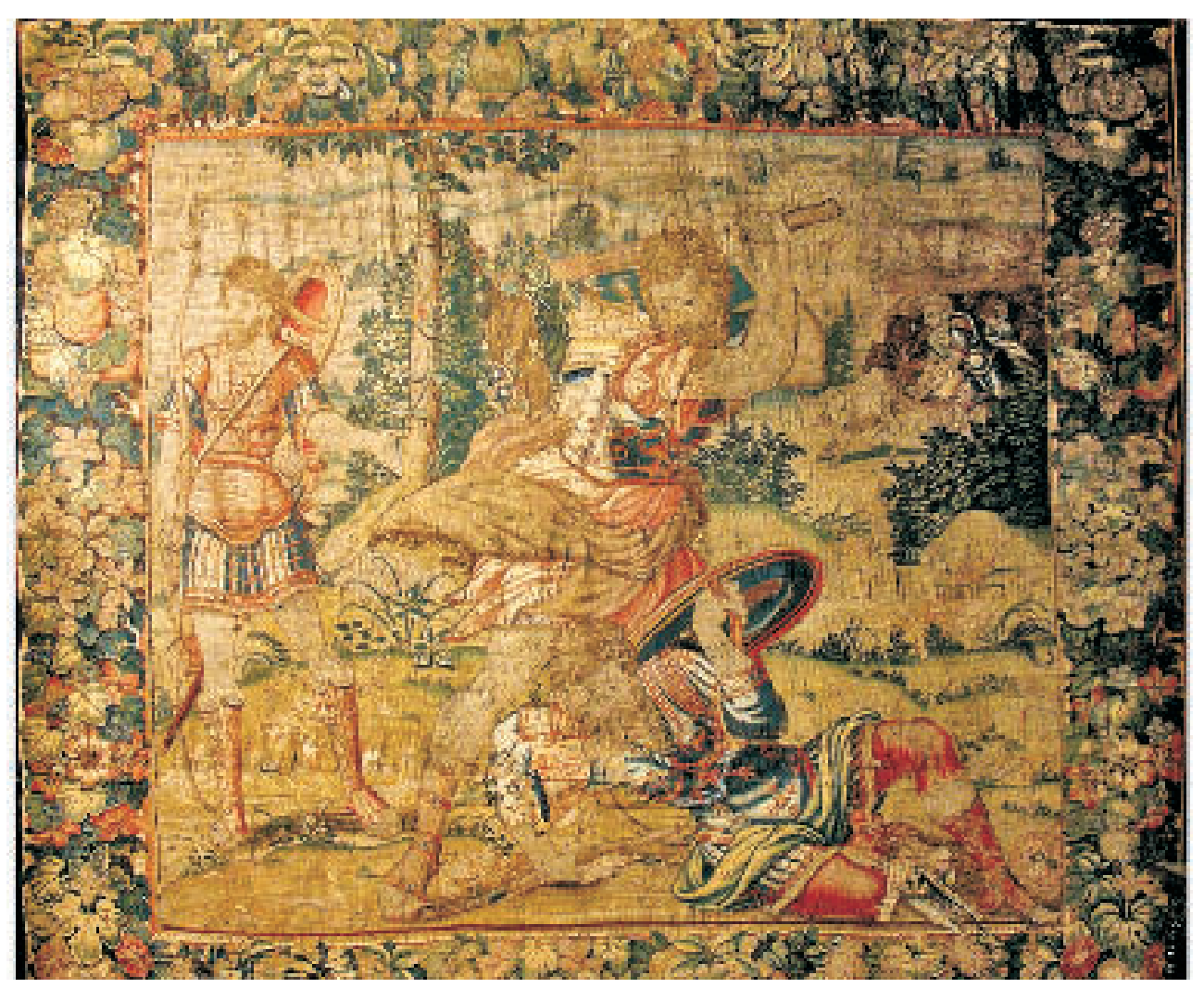

Fig. 6. Tapiz de la Historia de Sansón. Ayuntamiento de Ávila.

la derecha, que representa a Sansón atando una tea a la cola de las zorras, permite identificar el tema.

Otro comprador en esta almoneda de los tapices de Pedro de Toledo fue el VII conde de Siruela, Gabriel de Velasco y la Cueva, casado con Victoria Pacheco, hija del marqués de Cerralbo, que el 10 de noviembre 1636 compra "las tapicerías 2 y $11----22.830$ reales" 50 , de las que no se dan medidas que nos permitan identificarlas, pero en el año 1689, en un inventario de bienes de Leonor de Velasco, XI condesa de Siruela y marquesa de Cerralbo, hecho a su muerte, aparece una "historia de Julio Cesar" 51 que coincide en número de paños, medidas y procedencia con la de D. Pedro, descrita en la tasación de 1627 como "fina de parís, de lana y seda...tiene cinco anas y media de cayda en 10 paños..." 52 . Desconocemos si la tapicería fue vendida en la almoneda que se hace en el mismo año de su muerte o siguió en poder de sus herederos, los marqueses de Cerralbo y los duques de Siruela. Este último título se incorpora a la Casa de Alba

50 ADMS, leg. 4995.

51 "Una tapizeria de diez paños fina fabrica de paris dela historia de Julio Cesar de zinco anas y tercia de cayda y quarenta y siete anas y media de corrida queen todo hacen duzientas y cinquenta y tres anas y una tercia que se taso cada una a sesenta reales de vellon importan quinze mil y ducientos reales” (AHPM, núm. 9819, fol. 1583v).

52 ADMS, leg. 4885. Apéndice. 
en el siglo XIX al contraer matrimonio María del Rosario Falcó y Osorio con Carlos María Stuart Fitz James.

También son citados otros compradores, como Francisco Sáez de Anabe que "debe en 5 de junio de 1636 tapicerias de 130 anas a 36 reales-----4680 reales" 53 . Las medidas que se dan coinciden con las "fabulas de anteón y boscajes", tejidas en Bruselas según la tasación de 1627, y que son escenas de Diana y Acteón, inspiradas en las Metamorfosis de Ovidio. Julio de Morales, alcalde de Casa y Corte, compra el 5 de agosto de 1636 "la tapicería n. ${ }^{\circ} 8$ de 286 anas a 62 reales-----17732 reales" ${ }^{54}$. Posteriormente se quejó de que la tapicería no estaba bien medida ya que tenía cuatro anas menos y quería que le devolviesen los 248 reales que había pagado de más. Por la similitud de las medidas podría ser la Historia de Alejandro de ocho paños, hecha en Bruselas. La última compra que refleja la almoneda la hacen "D. Pedro y D. Iñigo para su casa en salamanca". Compran la tapicería n. $^{\circ} 12$, de la que no se proporcionan datos.

Aunque sólo está documentada la venta de ocho conjuntos, suponemos que en esta almoneda se vendieron la mayoría de los tapices de Pedro de Toledo. Algunos han llegado hasta nuestros días y forman parte de la colección de Patrimonio Nacional, como ya hemos comentado. De otros, por ahora, sólo tenemos las referencias que nos proporcionan los archivos. Refuerza esta teoría de la venta el hecho de que en un inventario de tapices que se hace en 1708, tres años después de la muerte del VII marqués de Villafranca, Fadrique de Toledo (†1705), sólo reconozcamos como herencia de la magnífica colección de tapices de su abuelo los diez reposteros hechos en Milán.

\section{APÉNDICE \\ "Entrega que se hace a Pedro Bergeret Guardarropa de D. Pedro de Toledo mi señor de toda la guardarropa recamara y plata que estaba a cargo de Julio de Encinas que se le entregara en la manera siguiente"}

"siete paños fina de flandes de galerías con volatería forradas las cenefas en angeo"

"mas otra tapicería fina de Flandes de historia de faetón de cinco paños y de seis anas de caída"

"mas una tapicería de alexandro magno fina de lana y seda echa en bruselas de ocho paños y de seis anas de caída y entodas quatrocientas y diez anas"

"mas otra tapicería de la misma historia de alexandro con bolateria en las cenefas que consiste en diez paños de trecientas anas en todas y de seis anas de caída"

"una tapicería basta de montería y payses de cinco paños"

"otra tapicería de once paños de la historia de sansón de Flandes"

"mas la tapicería rrica de siete paños hecha en parís finissima con oro y plata de historia de diana con las armas de toledos y ossorios. Mas el dosel desta colgadura entero"

"mas otra tapicería de la historia de audinarda de lana vasta en siete paños"

"mas una tapicería fina de lana y seda de parís historia de artemissa que consiste en ocho paños mas su dosel entero"

"Tasación de las tapicerías de Pedro de Toledo Osorio, marqués de Villafranca.

Hecho en Madrid a, a cinco días del mes de enero de 1627"

${ }^{53}$ ADMS, leg. 4995.
54 ADMS, leg. 4995.

AEA, LXXXIII, 332, OCTUBRE-DICIEMBRE 2010, 347-362, ISSN: 0004-0428 
Tapiçerias-----

"10 paños-----Una tapiçeria fina de parís de lana y seda de la ystoria de julio cesar que tiene cinco anas y media de cayda en 10 paños y 279 anas tasada a 120 reales la ana monta-----33.480 reales"

"5 paños"------Otra tapiçeria de la ystoria de faetón labrada en anguien tiene seis anas de cayda y 36 decorida que hacen 216 anas a 55 reales la ana monta-----11.880 reales"

"6 paños-----otra tapiçeria de la ystoria de metamorfosis que tiene seis anas y quarta de cayda y decorida 31 y en todas 194 anas a 44 reales la ana monta-----8.538 reales"

"7 paños-----otra tapiçeria de galerías fina de bruselas que tiene siete paños y cinco anas de cayda y 38 anas media decorida que hacen 193 anas a 100 reales la ana-----19.300 reales"

"5 paños-----otra tapiçeria de las fabulas de anteón y boscajes hecha en bruselas son cinco paños los tres grandes y dos pequeños de cinco anas de cayda y 26 decorida hacen 130 anas a 66 reales la ana----8.580 reales"

"10 paños-----otra tapiçeria fina de bruselas de la ystoria de marco antonio y cleopatra con la cenefa alta de bolateria que tiene diez paños seis anas de cayda y sesenta y siete decorida, que hacen 402 anas a 110 reales cada una monta-----44.220 reales"

"8 paños hecha en bruselas-----otra tapiçeria de la ystoria de alexandro que tiene seis ans de cayda y 45 decorida que hacen 291 anas a 132 reales monta-----38.412 reales"

"11 paños-----otra de la ystoria de sansón que tiene seis anas de cayda y 85 anas y media decorida que hacen 513 anas a 70 reales la ana-----35.910 reales"

"8 paños-----otra de la ystoria de artemisa rica y nueva que tiene 6 anas de cayda y 58 anas y media decorida que hacen 351 anas a 200 reales tasa una monta 70.200 reales.-----el dosel desta tapiçeria tiene 43 anas con sus cenefas a 220 reales cada una-----9.460 reales"

"7 paños-----otra tapiçeria rica de oro y seda nueva de la ystoria de diana, tiene siet anas de cayda y 58 decorida que hacen 406 anas a 500 reales cada una-----203.000 reales. El dosel desta colgadura de oro y seda tiene 48 anas a 660 reales monta treinta y un mil seiscientos y ochenta reales-----31.680 reales"

$$
\text { Total-----514.660 reales }
$$

" 10 reposteros de tapiçeria-----diez reposteros de seda y plata que tiene cada uno 15 anas que en todo son 150 a 110 reales la ana monta 16.500 reales-----16.500 reales"

(ADMS, leg. 4885)

Fecha de recepción: 14-IV-2009

Fecha de aceptación: 17-VI-2009 